\title{
Sclerosing Signet Ring Cell Carcinoma of the Lacrimal Gland: A Potentially New Primary Entity
}

\author{
Frederick A. Jakobiec ${ }^{a}$ Edith R. Reshef ${ }^{a}$ Lina Ma ${ }^{a}$ Martin K. Selig ${ }^{c}$ \\ Daniel R. Lefebvre ${ }^{b}$ Anna M. Stagner ${ }^{a, c}$
}

a David G. Cogan Laboratory of Ophthalmic Pathology, Department of Ophthalmology, Massachusetts Eye and Ear, Harvard Medical School, Boston, MA, USA; b Division of Ophthalmic Plastic Surgery, Department of Ophthalmology, Massachusetts Eye and Ear, Harvard Medical School, Boston, MA, USA; 'Department of Pathology, Massachusetts General Hospital, Harvard Medical School, Boston, MA, USA

\section{Established Facts}

- The most common lacrimal gland epithelial malignancy is adenoid cystic carcinoma followed by adenocarcinoma.

- In common with other epithelial tumors of the head and neck, especially those of the salivary gland, an exclusively sclerosing primary signet ring carcinoma of the lacrimal gland has never been described.

- The closest simulants of this condition are primary sclerosing carcinoma of the eyelids, arising from eccrine or apocrine glands, or metastatic lobular breast carcinoma.

\section{Novel Insights}

- A primary sclerosing signet ring carcinoma may occur in the lacrimal gland as a most exceptional lesion.

- This tumor must be distinguished from metastatic lobular breast carcinoma.

- The diagnosis of a primary signet ring carcinoma in the lacrimal gland cannot be made by immunohistochemistry alone, because of overlaps with primary eyelid and metastatic breast signet ring tumors.

- A thorough systemic work-up should be done to rule out a primary tumor elsewhere.

- Electron microscopy is presently essential in making the diagnosis by demonstrating acinar-type zymogen granules synthesized by the tumor cells.

\section{Keywords}

Lacrimal gland - Orbit - Signet ring carcinoma - Sclerosing .

Scirrhous carcinoma - Metastatic carcinoma .

Mucus-producing carcinoma $\cdot$ Immunohistochemistry .

Electron microscopy (c) 2020 S. Karger AG, Basel

www.karger.com/oop

Karger!

\section{Abstract}

An 88-year-old man presented with diplopia, limitation of extraocular movements, and a firm palpable mass in the superolateral orbit. Biopsy revealed a sclerosing signet ring cell carcinoma with histopathologic features mimicking those of 
a primary signet ring cell (histiocytoid) carcinoma of the eyelid of eccrine or apocrine gland origin, a metastasis from an invasive lobular breast carcinoma or a metastatic diffusetype gastric carcinoma. An extensive panel of immunohistochemical stains and molecular genetic analyses unequivocally failed to establish a precise diagnosis. Electron microscopy demonstrated features of a primary lacrimal gland lesion with intracytoplasmic lumens and zymogen granules typical of lacrimal secretory pyramidal cells. A thorough initial systemic work-up failed to reveal a primary visceral malignancy. Fifteen months of follow-up have failed to detect the emergence of another primary malignancy. To the best of our knowledge, a tumor with the morphology of the current lesion has not been previously described in the major or accessory lacrimal glands.

(c) 2020 S. Karger AG, Basel

\section{Introduction}

Sclerosing signet ring cell carcinomas are rare histomorphologic types of mucin-producing adenocarcinomas [1-4]. This morphology is usually seen in primary lobular breast carcinomas and their metastases, and in a subset of stomach, pulmonary and colonic carcinomas (90\% of all cases). When encountered in the orbit and other adnexa, it is overwhelmingly indicative of metastatic lobular breast cancer [5]. Signet ring cell tumors have not yet been described among metastases to the lacrimal gland (Table 1) [6]. Infrequently signet ring cells may be focally observed, in but not universally constitutive of, non-sclerosing glandular tumors of the head and neck, including those of the salivary glands [7, 8]. However, sclerosing signet ring arising from the cutaneous apocrine or eccrine glands of the eyelids and other cutaneous sites have been repeatedly reported [921].

The patient described herein had a firm lacrimal fossa mass that did not infiltrate the eyelid skin. The tumor had grown slowly causing diplopia from limitation of extraocular motility. Histopathologic, immunohistochemical and electron microscopic evaluations disclosed a primary sclerosing (scirrhous or desmoplastic) signet ring carcinoma of probable lacrimal gland origin, a potentially new ophthalmic entity. There was no prior or contemporary evidence of a distant primary visceral malignancy, which would have indicated that the orbital tumor was a metastasis.
Table 1. Metastatic tumors reported in the lacrimal gland

\begin{tabular}{ll} 
Type of carcinoma & $\begin{array}{l}\text { Reporte } \\
\text { cases }\end{array}$ \\
\hline
\end{tabular}

Breast 9

Neuroendocrine tumor (kidney, ileum, mediastinum) 4

Renal cell carcinoma

Small cell carcinoma lung

Esophageal squamous cell carcinoma

Thyroid carcinoma

Hepatocellular carcinoma

Malignant pleural mesothelioma

Choriocarcinoma of uterus

Mucus-producing carcinoma (site unspecified)

Total

23

Modified from [6], p. 170, table 5.01.

\section{Materials and Methods}

As a case report based on archived pathologic tissue, Institutional Review Board approval was not necessary for the research performed in this study. Medical records, including clinical photographs, the results of the ocular and orbital examinations and imaging studies were retrieved and critically reviewed. Paraffinembedded sections were stained with hematoxylin and eosin, periodic acid Schiff reaction, Alcian blue and mucicarmine. An extensive immunohistochemical panel (Tables 1,2) was employed in an attempt to establish a precise diagnosis. Additionally, multiple small fresh tissue fragments obtained at the time of surgery were primarily placed in glutaraldehyde fixative and studied in thick $(1 \mu)$ plastic sections stained with toluidine blue. These sections were used for orientation and detection of representative portions of the tumor. Appropriate tissues were selected for ultra-thin sectioning and stained with osmium tetroxide to be evaluated with transmission electron microscopy. Anchored Multiplex PCR using next-generation sequencing (Illumina NextSeq) for single nucleotide variant and insertion/deletion detection as well as targeted fusion transcript detection was performed after total nucleic acid extraction isolation from paraffin-embedded tumor (fusion detection with ArcherDx FusionPlex Solid Tumor Kit primers).

\section{Case Presentation}

\section{Clinical History}

An 88-year-old man was referred to an ophthalmic plastic surgeon for ocular irritation and diplopia. The patient had experienced 4-6 months of right eye irritation that had not responded to various topical steroid treatments. Soon thereafter he developed diplopia outside of primary gaze and a right orbital mass was noted. His medical history included hypertension, hyperlipidemia, chronic obstructive pulmonary disease and anxiety. The patient gave a 60-pack-year smoking history. There was no prior history of malignancy, ocular surgery or trauma. 
Table 2. Typical immunohistochemical prolife of common metastatic tumors to the orbit displaying signet ring cell morphology

\begin{tabular}{|c|c|c|c|c|c|c|}
\hline & \multirow{2}{*}{$\begin{array}{l}\text { Present } \\
\text { tumor }\end{array}$} & \multicolumn{5}{|c|}{ Primary tumor site of origin } \\
\hline & & $\begin{array}{l}\text { breast (lobular } \\
\text { carcinoma) }\end{array}$ & gastric & lung & colon & pancreatic \\
\hline CK7 & + & + & + & + & - & + \\
\hline CK20 & - & - & $+/-$ & - & + & $-/+$ \\
\hline AR & + & + & - & - & - & - \\
\hline GATA-3 & + & + & - & - & - & Rare \\
\hline GCDFP-15 & + & + & - & Rare & - & - \\
\hline ER & - & + & - & - & - & - \\
\hline $\mathrm{PR}$ & - & + & - & - & - & - \\
\hline E-cadherin & $-($ lost $)$ & $-($ lost $)$ & $+/-^{*}$ & + & + & + \\
\hline HER-2 & $2+$ & - & $+/-^{*}$ & - & - & - \\
\hline Mammaglobin & - & + & - & - & - & - \\
\hline $\mathrm{CDX} 2$ & - & - & $+/-$ & Rare & + & $+/-$ \\
\hline $\begin{array}{l}\text { Synaptophysin/ } \\
\text { Chromogranin }\end{array}$ & - & - & $\#$ & \# & $\#$ & $\#$ \\
\hline SATB2 & - & - & $-* *$ & -** & + & -** \\
\hline SMAD4 & + & + & $+* * *$ & $+* * *$ & $+* * *$ & - (lost) \\
\hline TTF-1 & - & - & Rare & + & - & - \\
\hline
\end{tabular}

\# Poorly differentiated adenocarcinomas of many sites may display expression of neuroendocrine markers. * A subset of gastric adenocarcinomas shows either loss of E-cadherin expression or HER2 amplification. ${ }^{* *} 10-20 \%$ of gastric, pancreatic and lung adenocarcinomas may show only focal expression. ${ }^{* * *}$ Advanced gastric, lung and especially colonic adenocarcinomas may show loss of SMAD4, which have a negative prognostic significance. CK, cytokeratin; AR, androgen receptor; GCDFP, gross cystic disease fluid protein; ER, estrogen receptor; $\mathrm{PR}$, progesterone receptor; TTF, transcription termination factor.

On ophthalmic examination, visual acuity was $20 / 40$ in the right eye and 20/60 in the left. The pupils were equal and reactive to light with no afferent pupillary defect; intraocular pressures were within normal limits. A smooth, firm, palpable mass was found to be centered at the anterior superolateral orbit and extended circumferentially superiorly and inferiorly around the globe (Fig. 1a). The eyelid skin was non-indurated and was readily movable over the underlying mass. There was $2 \mathrm{~mm}$ of right upper eyelid ptosis with grossly normal levator function. A distinct restriction of extraocular movements of the right eye was detected. The remainder of the extraocular and intraocular ophthalmic examination was normal bilaterally.

A computed tomographic study of the face and orbits revealed marked diffuse enlargement and enhancement of the right lacrimal gland, continuous with an ill-defined, enhancing soft tissue mass that embraced the antero-lateral margin of the right globe. It was inseparable from the lateral rectus, superior rectus, levator complex, inferior rectus, inferior oblique and inferior aspect of the medial rectus muscles. There was no adjacent osseous erosion (Fig. 1b-d). The mass was clearly centered in the orbit and not in the eyelid tissue, although the lateral portion of the eyelid was pushed forward by the anterior border of the mass.

A systemic work-up including a thorough breast examination, mammogram, full body positron emission tomographic scan and upper gastrointestinal endoscopy was negative for a primary visceral malignancy. Following several conversations with the pa- tient, and after the diagnostic results of a subtotal biopsy that removed about two thirds of the mass located behind the orbital septum, a decision was reached to proceed with adjuvant radiation therapy because the patient opposed aggressive surgical treatment. Fifteen months post-operatively and 13 months following the completion of radiation therapy, the patient continues to do well without eye pain, irritation, or other evidence of radiation-related complications. Repeat computed tomography and examinations of the orbit have failed to reveal progressive growth of the residual tumor or evidence of extraorbital spread and signs of systemic metastatic disease from a non-orbital primary malignancy.

\section{Histopathologic Findings}

The mass was placed in formalin with a smaller portion divided into $1 \mathrm{~mm}^{3}$ cubes and fixed in glutaraldehyde. The excised portion of the tumor consisted of fragments of dense fibrous tissue measuring $3.7 \times 3.6 \times 0.5 \mathrm{~cm}$ in aggregate. Low power microscopic examination disclosed a dense collagenous matrix with a dispersal of single cells that had infiltrated and replaced the orbital fat (Fig. 1e). Higher power microscopy disclosed either single cells or dyscohesive cells in a single file arrangement. In one focus of preserved fat cells, loosely arranged neoplastic cells were identified between individual adipocytes. The cells were round to ovoid with a high nuclear to cytoplasmic ratio (Fig. 1f). The tumor cells in the orbital fat displayed a polygonal shape, moderate amounts of eosinophilic cytoplasm, and some degree of nuclear pleomorphism 
Fig. 1. Clinicopathologic features of primary lacrimal gland signet ring carcinoma. a An 88-year-old man developed ocular irritation and diplopia over 6 months. The right orbit was full due to a superolateral palpable, firm mass that had narrowed the inter-palpebral fissure, shallowed the orbital-palpebral upper eyelid sulcus, and displaced the globe downwards. b An axial computed tomogram displays a lateral soft tissue density (arrow) molded to the globe. c A coronel tomogram better delineates the extent of the mass (arrows). There is no adjacent bone destruction and the sinuses and nasal passageways are clear except for some antral mucosal thickening. d A sagittal tomogram demonstrates tracking of tumor posteriorly along the surface of the superior rectus muscle (arrow). e Microscopically the tumor is dominated by marked fibrosis with a pseudoinflammatory dispersal of widely separated individual cells. In this field there is a focus of hypercellularity (arrow). f The round tumor cells adopt a single file columnated growth pattern (arrow; e, $\mathbf{f}$ hematoxylin and eosin, $100 \times$ and $400 \times$ respectively).
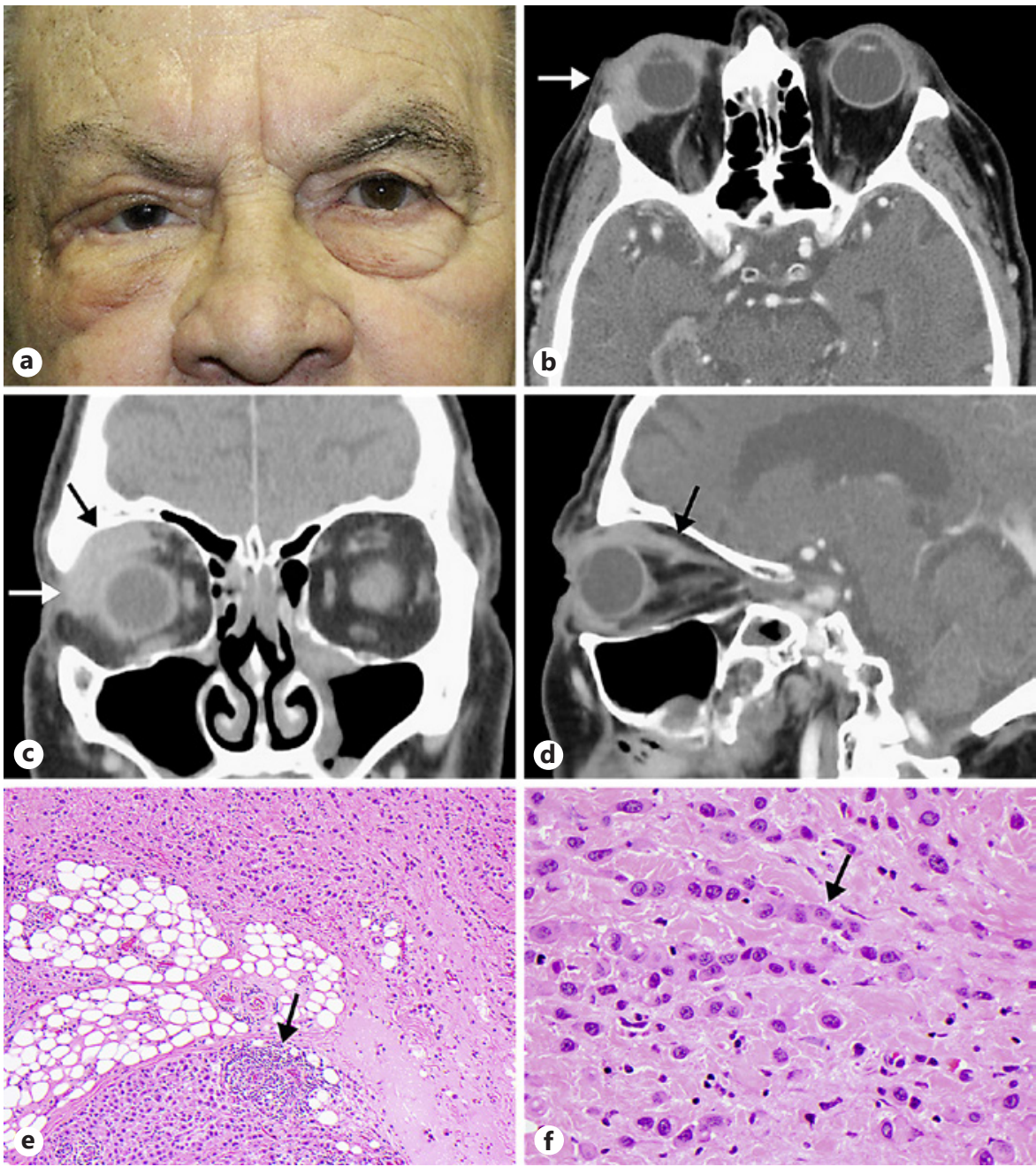

(Fig. 2a). In these zones, small collections of lymphocytes were also seen. The Alcian blue (Fig. 2b) and mucicarmine (Fig. 2c) stains demonstrated that around $10 \%$ of the tumor cells contained intracellular mucin in large single vacuoles that displaced the nucleus to the cell's periphery, in the manner of signet ring cells. The Gomori methenamine silver stain demonstrated an affinity for mucin and also accentuated the signet ring cell cytomorphology (Fig. 2b, inset). The Masson trichrome stain disclosed fine red granules in scattered tumor cells' cytoplasm (Fig. 2d). The phosphotungstic acid hematoxylin stain (Fig. 2e) also highlighted the same granules with a blue coloration.

\section{Immunohistochemical and Molecular Genetic Studies}

The immunohistochemical stains employed in the evaluation of the tumor cells are listed in Table 1. The positive staining results included positivity for keratin 7 (Fig. 2f), GATA3 (Fig. 3a), gross cystic disease fluid protein-15 (GCDFP-15; Fig. 3b) and androgen receptor (Fig. 3c); the neoplastic cells displayed a Ki67 proliferation index of around $10-15 \%$ (Fig. 3d). No staining was detected with myoepithelial markers (S100, calponin, p63); immunostains for SOX10 and DOG1 were also negative. HER-2 immunostaining was graded as 2+; however, HER-2 amplification was not identified using FISH. A targeted next generation sequencing assay identified a CDH1 single nucleotide variant (ENSP00000261769.4:p. Trp526Ter). No gene fusions were identified using an Anchored Multiplex polymerase chain reaction-based fusion assay.

\section{Electron Microscopic Analysis}

Electron microscopic analysis revealed polygonal cells with ample cytoplasm and nuclei exhibiting dispersed euchromatin and a prominent ropey nucleolus (Fig. 4a). Clusters of cells forming a central lumen were not seen. The cells often manifested focal surface villi (Fig. 4b). No basement membrane was seen along the plasmalemmas of the tumor cells where they abutted the collagenrich sclerotic stroma. Only fibroblasts but no myoepithelial cells with cytoplasmic filaments exhibiting fusiform densities were found in the stroma. The salient cytoplasmic features of the tumor cells included numerous small vesicles (Fig. 4c) often containing flocculent material (Fig. 4d), scattered mitochondria, and groups of large zymogen-type electron-dense granules (Fig. 4a), the last observed in about $20 \%$ of cells. Cytoplasmic myofilaments were not seen in the cytoplasm of the tumor cells. A striking feature was 
Fig. 2. Higher power microscopic evaluation of tumor cells including special stains. a A non-desmoplastic region of the orbital fat contains a disorganized cluster of atypical, polygonal, dyscohesive tumor cells with intermingled lymphocytes (arrow). b The Alcian blue stain reveals many positive cells, which have an intracellular mucus content delimited by a large cytoplasmic vacuole (arrows). The inset represents the Gomori methenamine silver stain of positive mucus vacuoles (arrow), which had displaced the nuclei (crossed arrow). These are referred to as a signet ring cells. c The mucicarmine stain also manifests an affinity for staining the large mucus vacuoles (arrow). d The phosphotungstic acid hematoxylin stain highlights a fine cytoplasmic, blue-staining granularity in the cytoplasm. e The Masson trichrome stain brings out the red staining property of the cytoplasmic granules (arrows). f Cytokeratin 7 is uniformly positive in the tumor cells and reinforces the impression of a single file cellular disposition (a, hemotoxylin and eosin, 400×; b, alcian blue, 600×, insert, gomori methenamine silver, $600 \times$; c, mucicarmine 600x; d, PTAH, 600×; e, Masson trichrome, $600 \times$; f, cytokeratin 7, 100x; immunoperoxidase reaction, diaminobenzidine chromogen, hematoxylin counterstain).

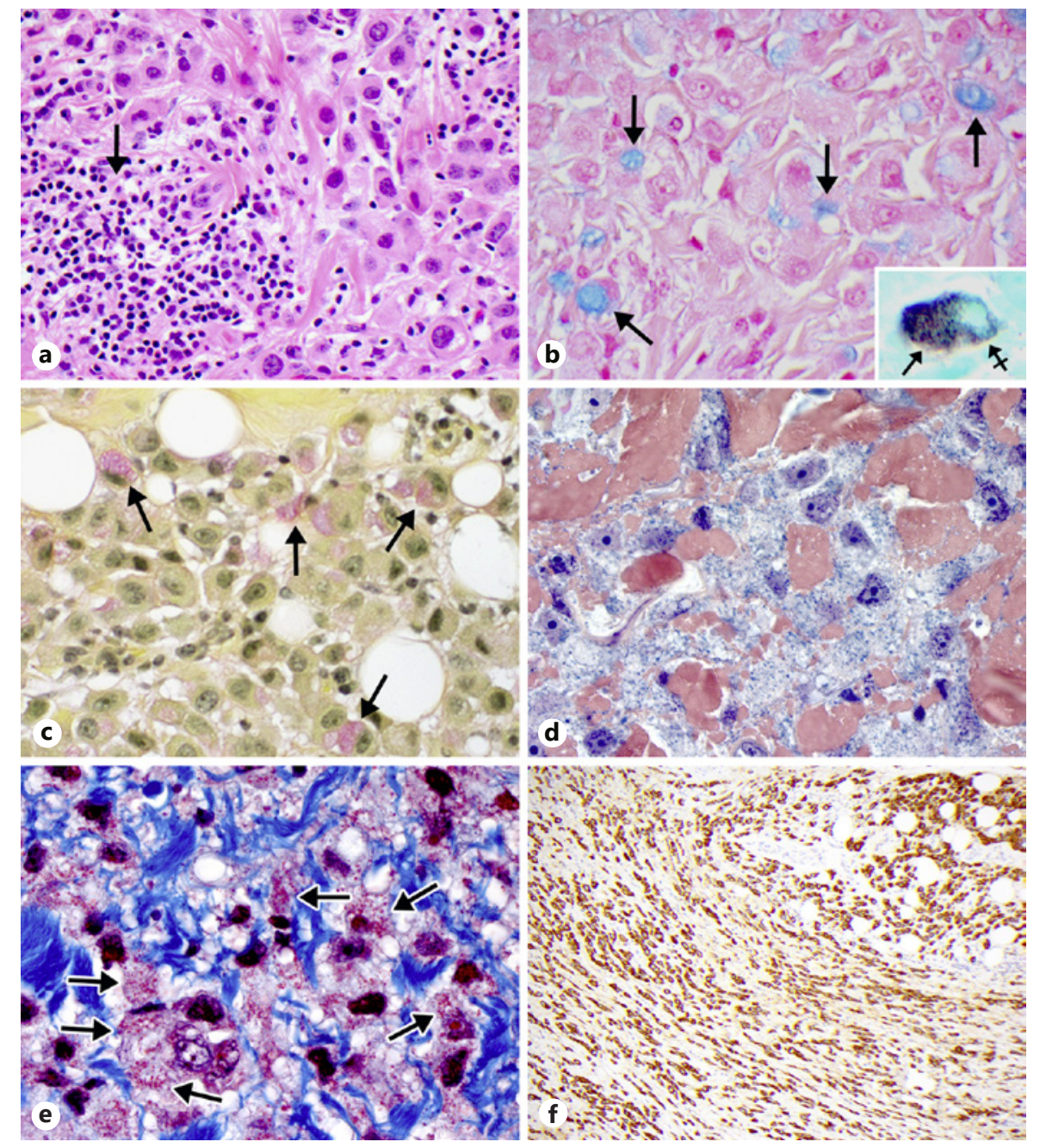

the presence of intracytoplasmic lumina with inwardly projecting microvilli (Fig. 4a). Myriad flocculent granules were arranged around these lumina, suggesting discharge into the cytoplasmic lumina of mucus inclusions (Fig. 4b). Cells in mitosis or undergoing apoptosis were not observed.

\section{Discussion}

\section{Clinical Aspects}

The present mature adult male patient became symptomatic about 6 months before he was evaluated by an orbital specialist. He complained of fullness of the right lateral upper eyelid accompanied by diplopia. There was no evidence of skin erythema, a cutaneous nodule or mass, or induration of the skin. The skin was movable over a palpable, firm subcutaneous mass in the superior, anterolateral region of the orbit. Lacrimal fossa lesions with symptoms of 6 months duration or less are typically either inflammatory conditions or epithelial malignancies [22].

The computed tomographic study disclosed an oblong and molded lacrimal fossa lesion without accompanying bone changes. It was obviously located in the orbit and not the eyelids, which displayed no CT or MRI evidence of extension into these tissues owing to a lack of increased soft tissue density. Both the palpebral and orbital lobes appeared involved, the former indicated by some extension of the overall mass mildly beyond the orbital rim. Anterior displacement of the lateral portion of the upper eyelid was noted. These findings were indicative of an inflammatory disorder, contrasting with to the round or oval shape of epithelial tumors that usually originate in the deep orbital lobe of the gland [22]. There was, however, countervailing imaging evidence in sagittal cuts of the superior orbit showing solid tumor extension into the 
Fig. 3. Positive immunohistochemical results for select biomarkers. a GATA 3, typically present in breast carcinoma, is positive in scattered tumor cells $(400 \times)$. b GCDFP-15 exhibits moderate to intense positivity in the tumor cells $(200 \times)$. c Androgen receptors were detected in a majority of the tumor cells' nuclei $(400 \times)$. d Ki 67 demonstrates nuclear positivity with a proliferation index of approximately $10 \%$ of cells in a DNA replicative phase (immunoperoxidase reacts on all $200 \times$ ).
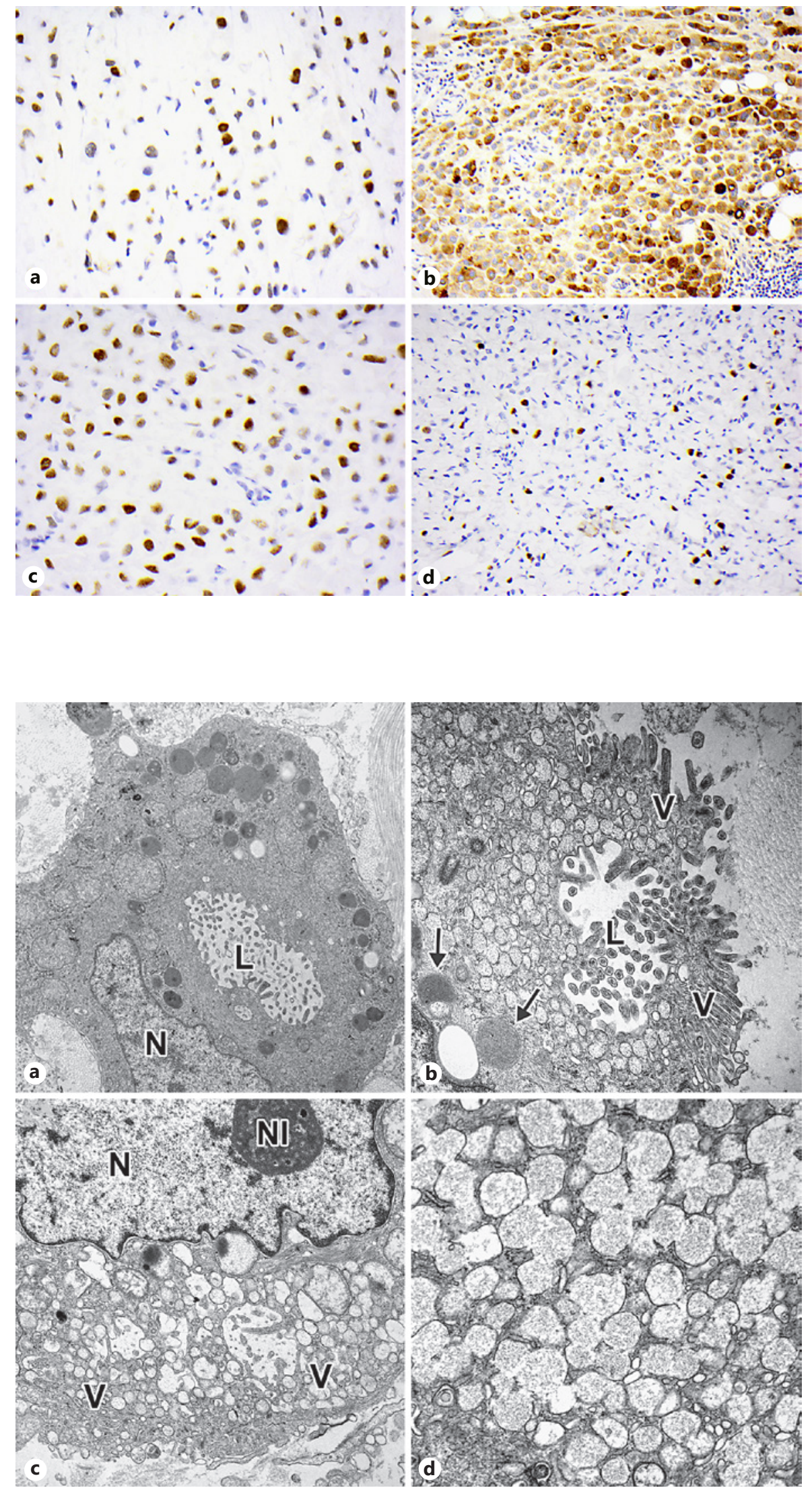

Fig. 4. Ultrastructural findings in tumor cells. a An overview of a typical tumor cell. There is a large intracytoplasmic lumen (L) with inwardly projecting villi creating a signet ring character. The cytoplasm is endowed with numerous large electron-dense secretory (zymogen) granules. ( $\mathrm{N}$, nucleus). b An intracytoplasmic lumen (L) with villi (V) is present near the cytoplasmic limiting membrane, which displays its own cell surface villi. Myriad small vesicles are oriented around the intracytoplasmic lumen prior to discharging their mucoid contents into it. The arrows indicate nearby zymogen granules. c A collection of small vesicles $(\mathrm{V})$ of mucus, is interposed between the nucleus $(\mathrm{N})$ with its prominent nucleolus (NL) and the cell's plasmalemma below. The vesicles are derived from the Golgi zone represented by the variably dilated membranous profiles. d Higher power evaluation of the mucus inclusions reveals that they possess a flocculofibrillar content similar to that seen in goblet cells. (transmission electron micrographs, ultrathin sections stained with osmium tetroxide: (a, 3,400x; b, 14,000×; c, $9,100 \times ; \mathbf{d}, 11,000 \times)$.
Ocul Oncol Pathol 2020;6:265-274

DOI: $10.1159 / 000505490$
Jakobiec/Reshef/Ma/Selig/Lefebvre/ Stagner 
deeper orbital tissues above the superior rectus muscle, a finding compatible with a malignancy. This led to the performance of a biopsy with removal of around two thirds of the tumor, which established the diagnosis of a sclerosing (scirrhous) infiltrating carcinoma, a type of lesion in the periocular adnexa that is most frequently observed in metastatic lobular carcinoma of the breast [5]. The patient was a man without any signs on physical examination of a tumor in his minimal breast tissue. Orbital metastases from breast carcinomas, however, have rarely been reported in male patients and patients without clinically detectable breast lesions $[23,24]$. An exhaustive clinical work-up, including whole body positron emission tomographic scanning together with upper and lower endoscopies, failed to uncover a visceral malignancy.

\section{Light Microscopy of Orbital Lesion}

The salient microscopic features of the biopsy in this case consisted of uniformly dense fibrous tissue replacing the orbital fat and containing widely dispersed cells simulating an inflammatory lesion. No pre-existent normal lacrimal parenchyma was discovered in the biopsy; it was probably destroyed by the tumor or not sampled in the $30 \%$ of the mass left unsampled. In the past, the scattered cells displayed in the present lesion invited the diagnosis of a histiocytic disorder. High power microscopy, however, disclosed cells with a moderate amount of eosinophilic cytoplasm and hyperchromatic nuclei arranged in a columnated or single file pattern. Some cells displayed large intracytoplasmic mucinous vacuoles that displaced the nucleus to the cell's periphery, thereby qualifying them as signet ring cells. The Alcian blue and mucicarmine stains confirmed the presence of mucin in the large vacuoles, consistent with a signet ring adenocarcinoma. Earlier designations for this histopathologic appearance in the orbit or elsewhere were "histiocytoid" or "scirrhous" carcinoma [4]. It is now appreciated that such lesions in the orbit are overwhelmingly metastatic lobular breast carcinomas [5].

\section{Electron Microscopy}

Ultrastructural examination revealed polygonal cells $20 \%$, of which possessed large electron-dense secretory (zymogen) granules like those seen in lacrimal acinar pyramidal cells [25]. Zymogen granules are also found in tumors of the parotid, exocrine pancreas and bowel, the latter deriving from Paneth cells of the small intestine or chief cells of the gastric mucosa. These tumors are, however, remote possibilities for an orbital metastasis, particularly involving the lacrimal gland (Table 1). The nu-

Lacrimal Gland Signet Ring Cell

Carcinoma clei were large, displayed dispersed euchromatin, and possessed a prominent nucleolus with a ropey nucleolenema. Intracytoplasmic lumina manifesting villi were frequently seen in the tumor cells. Surface plasmalemmal villi were also present. No segments of basement membrane were identified, providing a morphologic basis for the absence of E-cadherin staining. The cytoplasm was endowed with a plethora of small vesicles containing a floccular content; they tended to be arranged around the intracytoplasmic lumina, corresponding to the signet ring cells seen with the Alcian blue and mucicarmine stains in the light microscopic sections. In several cells, there were massive collections of vesicles with an amorphous or flocculent, relatively electron-lucent content, consistent with the morphology of mucus granules seen in goblet cells [25]. The desmoplastic stroma harbored scattered fibroblasts responsible for the conspicuous collagen deposition, but no myoepithelial cells with cytoplasmic filaments manifesting fusiform densities were discovered, nor were myofilaments noted in the signet ring tumor cells. Previous reports with electron microscopic evaluations of primary signet ring carcinomas of the eyelid failed to reveal any large zymogen granules, but instead displayed only lysosomes or small non-zymogenic granules, possibly secretory in nature $[9,10,16,17]$. The foregoing findings were most consistent with an origin of the present tumor from the lacrimal gland secretory acinar cell (pyramidal or serous) or a pre-acinar terminal ductular cell with a biomorphic differentiation potentiality.

Microscopic Differential Diagnosis: Metastatic Disease

The differential diagnosis for a signet ring adenocarcinoma with single cell invasion and uniform and dense sclerosis in the orbit, overwhelmingly favors a metastatic breast carcinoma [5]. Among other possibilities, tumors of gastric and pancreatic origins are the most frequently associated with a prominent desmoplastic stromal reaction [26-37]. Table 1 lists the results of a review of metastatic tumors with an epicenter in the lacrimal gland [6]. Except for the breast carcinomas, none of the other tumors listed is known to exhibit a desmoplastic stroma.

Orbital metastatic gastric and pancreatic carcinomas are exceedingly rare. In a meticulous histopathologic series of 28 metastatic orbital tumors, of which 18 had a determination of origin [27], there was only one instance of pancreatic carcinoma but no mention of a gastric carcinoma. The pancreatic tumor displayed a single file growth pattern without a conspicuous sclerotic stroma. 
In a search of the literature for case reports, 5 additional examples of metastatic orbital pancreatic carcinoma were found [28-32]. The majority lacked detailed histopathologic descriptions and photomicrographs; none was described as sclerosing. A similar search for gastric carcinomas turned up 5 case reports [33-37]. Again, the majority had suboptimal pathologic documentation, but only one case manifested a sclerotic, single-file pattern of spread [34]. Of some interest is that there is a peculiar tendency for both metastatic gastric and pancreatic carcinomas to lodge in the vicinity of optic nerve at the orbital apex.

Using immunohistochemistry (Table 2) [38], the neoplastic cells in the current orbital metastasis exhibited staining for GATA-3, androgen receptor and GCDFP-15, all of which typically are positive in breast and certain variants of salivary gland tumors with apocrine differentiation. Lobular breast cancer, however, is nearly always hormonally driven; estrogen and progesterone receptors are typically positive in the tumor. The absence of their expression in this case strongly argued against metastatic lobular carcinoma $[39,40]$. Additionally, lobular breast carcinoma characteristically evinces a strikingly banal, monomorphic morphology with a distinct lack of cellular pleomorphism, which differs from the presence of atypical cytologic features in our case.

Malignancies of colorectal (CDX2-, SATB2-), pancreatic (SMAD4 preserved), lung (TTF-), thyroid, hepatic (typically keratin 7-/20-), prostatic (PSA-), or neuroendocrine origin were also excluded (Table 1) [38]. Furthermore, molecular genetic features of colonic and pancreatic carcinoma, including single nucleotide variants in KRAS, were not identified using next-generation sequencing. Definitive exclusion of a gastric primary was provided by esophagogastroduodenoscopic examination.

\section{Microscopic Differential Diagnosis: Primary Tumors}

Originating in the Lacrimal Gland/Ocular Adnexa

With regard to primary salivary gland-type adenocarcinomas, mammary analog secretory carcinoma, highgrade mucoepidermoid carcinoma, salivary duct carcinoma (termed primary ductal adenocarcinoma in the lacrimal gland, the immunophenotype of which is most closely recapitulated by the current tumor), and acinic cell carcinoma were each considered in the differential diagnosis, since the foregoing tumors have been reported in the lacrimal gland $[6,41-44]$. However, although these entities may each display, some component of a signet ring cell morphology, a uniform population of these cells constituting the entirety of the tumor cells set in a prominent fibrous background is not characteristic. Additionally, immunohistochemical staining for SOX 10 and DOG1 (positive in acinic cell carcinoma), the $\mathrm{t}(12 ; 15)$ (p13;q25) ETV6-NTRK3 translocation of secretory carcinoma, and the $t(11 ; 19)$ CRTC1-MAML2 fusion characteristic of mucoepidermoid carcinoma were not detected in our case [45-47].

Two categories of primary salivary gland/lacrimal gland tumors that may indeed show overwhelming fibrosis and invade in a single cell fashion include (hyalinizing) clear cell carcinoma and myoepithelial (mucinous) carcinoma $[7,45,48]$. Furthermore, the more recently described mucinous myoepithelioma and secretory myoepithelial carcinoma have been morphologically described as signet ring cell (mucin producing) primary salivary gland adenocarcinomas [7, 48]. The current tumor showed no evidence of myoepithelial differentiation immunohistochemically or with electron microscopy. An EWSR1 fusion, characteristic of hyalinizing clear cell carcinoma, was also not detected $[45,46]$.

Primary signet ring cell/histiocytoid carcinoma, thought to derive from cutaneous apocrine or eccrine glands, has been reported on numerous occasions in the eyelid [9-21]. In addition to the significant morphologic overlap with lobular breast carcinoma and the current case [5], these tumors share immunohistochemical features as well [21]. They do, however, typically stain positively for p63 (in addition to keratin 7, GCDFP-15 and GATA3), which the current tumor did not. More importantly, the present tumor appeared to originate in the lacrimal gland due to its location deep to the skin rather than in the eyelid proper, as demonstrated both clinically, radiographically, and surgically during the biopsy. Primary signet ring cell carcinomas have also been shown to retain expression of e-cadherin, unlike the current case [12]. A review of previously reported primary eyelid signet ring carcinomas studied with electron microscopy failed to identify an example with the large zymogen granules [9, $10,16,17]$ that were observed in the current lesion and are characteristic of lacrimal secretory pyramidal cells [25].

Finally, consideration should be given to microcystic adnexal carcinoma of the eyelid skin $[49,50]$. This lesion has an epithelial component of small, lumen-forming units and small clusters of cells displaying horn cysts dispersed in a pronounced fibrotic stroma. The latter can induce ectropion of the involved eyelid, and if orbital extension occurs, enophthalmos as well. Duct or lumen formation and squamous differentiation were not manifested by the current tumor. 


\section{Conclusion}

The only uniformly sclerosing primary periocular adnexal signet ring carcinoma develops in the eyelid, where it derives from eccrine or apocrine sweat glands. It has never been reported in a major or minor salivary gland, in which family of tissues the lacrimal gland also belongs according to concepts in general pathology. Primary adenocarcinomas of the salivary glands have not been reported with an associated prominent sclerosis which has been uniformly present throughout the entire lesion. We have concluded that the current tumor is likely the first reported case of a primary, uniformly sclerosing (scirrhous) signet ring carcinoma of the lacrimal (or salivary glands). This tumor, therefore, potentially represents a new category within the nosology of lacrimal gland tumors. According to contemporary nomenclature, it should be classified, as recommended in the 4th edition of the WHO Classification of Tumors of the Eye, as an adenocarcinoma, NOS [6]. Fully establishing its distinctive character will depend on the discovery of a signature genetic alteration. Nonetheless, its distinctive morphology, after the exclusion of a metastasis or spread from a nearby primary tumor, confers confidence in and credence for providing a separate category among lacrimal gland tumors. A similar situation obtains with respect to primary lacrimal gland myoepithiomas and carcinomas, which have well defined morphologic characteristics but to date lack a specific genetic abnormality [6]. At the present moment, definitive treatment recommendations for the current tumor have not been agreed upon due to lack of prior experience. Given its extensive orbital involvement, the question of radical surgical excision with adjunctive radiotherapy must be balanced against the more conservative resort to proton beam treatment after judicious excisional debulking. The patient was opposed to any form of aggressive surgery; it was instead decided to apply supplemental proton beam therapy after the biopsy.

\section{Acknowledgments}

None.

\section{Statement of Ethics}

This study complies with the tenets of the Declaration of Helsinki and Health Insurance Portability and Accountability Act regulations. The clinical photographs have been cropped to protect the patient's identity. Nonetheless, all surgical consent forms signed by the patient at our institution contain an approval for the clinical photographs to be used in any future publications.

\section{Disclosure Statement}

The authors have no conflicts of interest to declare.

\section{Funding Sources}

Department of Ophthalmology Research Fund, Massachusetts Eye and Ear. This research did not receive any specific grant funding from referral agencies, public sources or, commercial and nonprofit sectors.

\section{Author Contributions}

Drs. Frederick A. Jakobiec, Edith R. Reshef, and Anna M. Stagner were responsible for the writing of the manuscript; Dr. Lina Ma was responsible for photomicrographs and shared in the pathologic analysis of the histopathology slides; Mr. Martin K. Selig performed the electron microscopy that was interpreted by Dr. Frederick A. Jakobiec; Dr. Daniel R. Lefebvre was the physician in charge of the patient care and supplied the clinical history and surgical findings; all of the authors helped to assemble the pertinent bibliography.

\section{References}

1 Chu PG, Weiss LM. Immunohistochemical characterization of signet-ring cell carcinomas of the stomach, breast, and colon. Am J Clin Pathol. 2004 Jun;121(6):884-92.

2 Kim JP, Kim SC, Yang HK. Prognostic significance of signet ring cell carcinoma of the stomach. Surg Oncol. 1994 Aug;3(4):221-7.

3 Jakobiec FA, Ramsey DJ, Stagner AM, Wu DM, Yoon MK. Pulmonary adenocarcinoma metastatic to the choroid diagnosed by biopsy of an extrascleral nodule. Ocul Oncol Pathol. 2015 Sep;2(1):24-8.
4 Hood CI, Font RL, Zimmerman LE. Metastatic mammary carcinoma in the eyelid with histiocytoid appearance. Cancer. 1973 Apr; 31(4):793-800.

5 Jakobiec FA, Stagner AM, Homer N, Yoon MK. Periocular breast carcinoma metastases: predominant origin from the lobular variant. Ophthal Plast Reconstr Surg. 2017 Sep/Oct; 33(5):361-6.
6 Grossniklaus HE, Eberhart CG, Kivela T. WHO Classification of Tumours of the Eye. Volume 12. 4th ed. Lyon: International Agency for Research on Cancer; 2018. pp. 147-70.

7 Bastaki JM, Purgina BM, Dacic S, Seethala RR Secretory myoepithelial carcinoma: a histologic and molecular survey and a proposed nomenclature for mucin producing signet ring tumors. Head Neck Pathol. 2014;8(3): 250-60. 
8 Singh M, Khurana N, Wadhwa R, Gulati A. Signet ring carcinoma parotid gland: a case report. Head Neck. 2011 Nov;33(11):1656-9.

9 Jakobiec FA, Austin P, Iwamoto T, Trokel SL, Marquardt MD, Harrison W. Primary infiltrating signet ring carcinoma of the eyelids. Ophthalmology. 1983 Mar;90(3):291-9.

10 Wollensak G, Witschel H, Böhm N. Signet ring cell carcinoma of the eccrine sweat glands in the eyelid. Ophthalmology. 1996 Nov; 103(11):1788-93.

11 Langel DJ, Yeatts RP, White WL. Primary signet ring cell carcinoma of the eyelid: report of a case demonstrating further analogy to lobular carcinoma of the breast with a literature review. Am J Dermatopathol. 2001 Oct;23(5): 444-9.

12 Requena L, Prieto VG, Requena C, Sarasa JL, Manzano R, Seco M, et al. Primary signet-ring cell/histiocytoid carcinoma of the eyelid: a clinicopathologic study of 5 cases and review of the literature. Am J Surg Pathol. 2011 Mar; 35(3):378-91.

13 Iwaya M, Uehara T, Yoshizawa A, Kobayashi Y, Momose M, Honda T, et al. A case of primary signet-ring cell/histiocytoid carcinoma of the eyelid: immunohistochemical comparison with the normal sweat gland and review of the literature. Am J Dermatopathol. 2012 Dec;34(8):e139-45.

14 Tan JS, McKelvie PA, Hardy TG. Primary signet ring cell carcinoma of the eyelid. Orbit. 2013 Dec;32(6):399-401.

15 Tanboon J, Uiprasertkul M, Luemsamran P. Signet-ring cell/histiocytoid carcinoma of the eyelid: a case report and review of the literature. Am J Dermatopathol. 2013 Feb; 35(1):e1-5.

16 Kramer TR, Grossniklaus HE, McLean IW, Orcutt J, Green WR, Iliff NT, et al. Histiocytoid variant of eccrine sweat gland carcinoma of the eyelid and orbit: report of five cases. Ophthalmology. 2002 Mar;109(3):553-9.

17 Kiyohara T, Kumakiri M, Kouraba S, Tokuriki A, Ansai S. Primary cutaneous signet ring cell carcinoma expressing cytokeratin 20 immunoreactivity. J Am Acad Dermatol. 2006 Mar;54(3):532-6.

18 Kim YM, Kim JW, Oh DE. A case of histiocytoid variant eccrine sweat gland carcinoma of the orbit. Korean J Ophthalmol. 2011 Feb; 25(1):54-6.

19 Khoramnia R, Mayer C, Glaser E, Weirich G. Primary signet ring cell carcinoma of the eyelid in a young woman. Eye (Lond). 2011 Oct; 25(10):1380-2.

20 Nazareth MR, Bogner P, Mansour N, Raghu PR, Mansour TN, Zeitouni NC. Primary adenocarcinoma of the eyelid with signet ring cell and histiocytoid features. Dermatol Surg. 2012 Nov;38(11):1882-5.

21 Yates JR, Mines MJ, Subramanian PS, RiveraMichlig R, Cummings TJ, Eberhart CG. Periocular histiocytoid carcinoma: potential diagnostic challenges. Ocul Oncol Pathol. 2019 Feb;5(2):94-101.
22 Jakobiec FA, Yeo JH, Trokel SL, Abbott GF, Anderson R, Citrin CM, et al. Combined clinical and computed tomographic diagnosis of primary lacrimal fossa lesions. Am J Ophthalmol. 1982 Dec;94(6):785-807.

23 Shields CL, Stopyra GA, Marr BP, Moster ML, Shields JA. Enophthalmos as initial manifestation of occult, mammogram-negative carcinoma of the breast. Ophthalmic Surg Lasers Imaging. 2004 Jan-Feb;35(1):56-7.

24 Torres JJ, Medel R, Alonso T, Morral M, García-Arumí J, Myint S, et al. Orbital metastases from male breast cancer in two cases. Ophthal Plast Reconstr Surg. 2007 Mar-Apr;23(2): 154-6.

25 Jakobiec FA, Iwamoto T. The ocular adnexa: Lids, conjunctiva, and orbit. In: Fine BS, Yanoff $M$, editors. Ocular Histology: A Text and Atlas. 2nd ed. Hagerstown (MD): Harper \& Row; 1979. pp. 289-342.

26 Shields JA, Shields CL, Brotman HK, Carvalho C, Perez N, Eagle RC Jr. Cancer metastatic to the orbit: the 2000 Robert M. Curts Lecture. Ophthal Plast Reconstr Surg. 2001 Sep;17(5): 346-54.

27 Font RL, Ferry AP. Carcinoma metastatic to the eye and orbit III. A clinicopathologic study of 28 cases metastatic to the orbit. Cancer. 1976 Sep;38(3):1326-35.

28 Geetha N, Chandralekha B, Kumar A, Ittiyavirah AK, Ramadas K, Joseph F. Carcinoma of the pancreas presenting as an orbital tumor: a case report. Am J Clin Oncol. 1998 Oct;21(5): 532-3.

29 Chand K, Panicker NK. Proptosis-an Unusual Presentation of Metastatic Carcinoma Pancreas: Case Report. Med J Armed Forces India. 1998 Oct;54(4):349-50.

30 Foo FY, Lee M, Looi A. Asymptomatic pancreatic adenocarcinoma presenting as an orbital metastatic tumor. Orbit. 2010 Oct;29(5):262-5.

31 Pecen PE, Ramey NA, Richard MJ, Bhatti MT Metastatic pancreatic carcinoma to the orbital apex presenting as a superior divisional third cranial nerve palsy. Clin Ophthalmol. 2012;6:1941-3.

32 Rong AJ, Choi CJ, Ghassibi MP, Dubovy SR, Johnson TE. Orbital metastatic small cell carcinoma of the pancreas with optic nerve compression. Can J Ophthalmol. 2018 Feb; 53(1):e22-4.

33 Seretan EL. Metastatic adenocarcinoma from the stomach to the orbit. Arch Ophthalmol. 1981 Aug;99(8):1469.

34 Yunker JJ, Vicinanzo MG, Braswell RA, Read RW, Goldin GF, Long JA. Unusual presentation of gastric adenocarcinoma metastatic to the orbit. Ophthal Plast Reconstr Surg. 2006 Nov-Dec;22(6):490-1.

35 Souayah N, Krivitskaya N, Lee HJ. Lateral rectus muscle metastasis as the initial manifestation of gastric cancer. J Neuroophthalmol. 2008 Sep;28(3):240-1.

36 Sitaula R, Shrestha GB, Paudel N, Shrestha JK. Ocular and orbital metastases presenting as a first sign of gastric adenocarcinoma. BMJ Case Rep. 2011 Dec;2011:pii: bcr1020114927.
37 Mutyala V, Bains S, Patil C, Madhavarao B. Bilateral acute ptosis leading to the diagnosis of a presumed metastatic gastric adenocarcinoma. Orbit. 2012 Apr;31(2):134-6.

38 Conner JR, Hornick JL. Metastatic carcinoma of unknown primary: diagnostic approach using immunohistochemistry. Adv Anat Pathol. 2015 May;22(3):149-67.

39 Arpino G, Bardou VJ, Clark GM, Elledge RM. Infiltrating lobular carcinoma of the breast: tumor characteristics and clinical outcome. Breast Cancer Res. 2004;6(3):R149-56.

40 Rakha EA, El-Sayed ME, Powe DG, Green AR, Habashy $\mathrm{H}$, Grainge MJ, et al. Invasive lobular carcinoma of the breast: response to hormonal therapy and outcomes. Eur J Cancer. 2008 Jan;44(1):73-83.

41 Bortz JG, Zhang PJ, Eagle RC Jr, Yong JJ, Milman T. Secretory carcinoma of the lacrimal gland: A rare case report. Ophthal Plast Reconstr Surg. 2018 Sep/Oct;34(5):e154-7.

42 Milman T, Shields JA, Husson M, Marr BP, Shields CL, Eagle RC Jr. Primary ductal adenocarcinoma of the lacrimal gland. Ophthalmology. 2005 Nov;112(11):2048-51.

43 Min KW, Park HK, Kim WY, Kim WS, Lim SD, Han HS, et al. Primary ductal adenocarcinoma of the lacrimal gland, associated with abundant intracytoplasmic lumens containing some eosinophilic hyaline globules: cytological, histological and ultrastructural findings. Ultrastruct Pathol. 2014 Oct;38(5):3636.

44 Hyrcza MD, Andreasen S, Melchior LC, Tucker T, Heegaard S, White VA. Primary secretory carcinoma of the lacrimal gland: report of a new entity. Am J Ophthalmol. 2018 Sep;193:178-83.

45 Zhu S, Schuerch C, Hunt J. Review and updates of immunohistochemistry in selected salivary gland and head and neck tumors. Arch Pathol Lab Med. 2015 Jan;139(1):55-66.

46 Wang K, Russell JS, McDermott JD, Elvin JA, Khaira D, Johnson A, et al. Profiling of 149 salivary duct carcinomas, carcinoma ex pleomorphic adenomas, and adenocarcinomas, not otherwise specified reveals actionable genomic alterations. Clin Cancer Res. 2016 Dec; 22(24):6061-8.

47 Skálová A, Stenman G, Simpson RH, Hellquist H, Slouka D, Svoboda T, et al. The role of molecular testing in the differential diagnosis of salivary gland carcinomas. Am J Surg Pathol. 2018 Feb;42(2):e11-27.

48 Gnepp DR. Mucinous myoepithelioma, a recently described new myoepithelioma variant. Head Neck Pathol. 2013 Jul;7(S1 Suppl 1):S85-9.

49 Hoang MP, Dresser KA, Kapur P, High WA, Mahalingam M. Microcystic adnexal carcinoma: an immunohistochemical reappraisal. Mod Pathol. 2008 Feb;21(2):178-85.

50 Dutton JJ, Gayre GS, Proia AD. Microcystic adnexal carcinoma. Diagnostic Atlas of Common Eyelid Diseases. New York (NY): Informa Healthcare; 2007. pp. 202-4. 